\title{
Effects of Intentional Weight Loss on Markers of Oxidative Stress, DNA Repair and Telomere Length - a Systematic Review
}

\author{
Caroline Himbert $^{\mathrm{a}, \mathrm{b}, \mathrm{c}}$ Henry Thompson ${ }^{d}$ Cornelia M. Ulrich ${ }^{\mathrm{a}, \mathrm{b}}$ \\ a Department of Population Sciences, Huntsman Cancer Institute, Salt Lake City, UT,

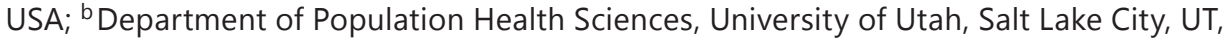 \\ USA; ' University Hospital Hamburg-Eppendorf, Hamburg, Germany; ${ }^{\mathrm{d}}$ Cancer Prevention \\ Laboratory, Colorado State University, Fort Collins, CO, USA
}

\section{Keywords}

Oxidative stress · DNA repair · Obesity $\cdot$ Weight loss

\begin{abstract}
Background: Altered levels of markers of oxidative stress, DNA repair, and telomere integrity have been detected in obese individuals and may underlie the pathogenesis of obesity-related diseases. However, whether or not such effects are reversed by intentional weight loss has not been systematically reviewed. Methods: A literature search in PubMed/Medline identified 2,388 articles of which 21 studies (randomized controlled trial $(R C T)(n=10)$ and non-randomized intervention studies $(n=11)$ ) were classified as testing the effects of intentional weight loss on i) oxidative stress $(n=15)$, ii) DNA repair $(n=2)$, and iii) telomere length $(n=4)$. $\boldsymbol{R e}$ sults: Across a broad range of intervention designs, diet-, exercise-, surgery-, balloon-induced weight loss regimens decreased oxidative stress measures. Studies investigating DNA repair capacity or telomere length as endpoints after weight loss were less common in number and yielded null or inconsistent results, respectively. Conclusion: While this systematic review supports a role for intentional weight loss in reducing obesity-associated oxidative stress, it is not clear whether the effects are primary outcomes or secondary to improvement in obesity-associated insulin resistance and/or chronic inflammation. Although the lack of effect of intentional weight loss on DNA repair capacity might be anticipated given that oxidative stress is reduced, additional studies are needed. The inconsistent effects of weight loss on telomere length or DNA repair suggest the need for a re-assessment of intervention designs and assay methodology to definitively address this topic.

(C) 2017 The Author(s)

Published by S. Karger GmbH, Freiburg
\end{abstract}


Himbert et al.: Effects of Intentional Weight Loss on Markers of Oxidative Stress, DNA Repair and Telomere Length - a Systematic Review

\section{Introduction}

Obesity is a major public health problem in the Western world, and the obesity pandemic is expected to persist over the next several decades [1]. 20\% of the general population in the US are obese (BMI $\geq 30 \mathrm{~kg} / \mathrm{m}^{2}$ ) [2]. Dyslipidemia, insulin resistance, and chronic inflammation are associated with obesity, and increased risk has been reported for type 2 diabetes, cardiovascular disease, and stroke. In addition, obesity results in an increased risk for multiple cancer types including cancers of the colon and rectum, endometrium, liver as well as esophagus [3,4]. Obesity is characterized by chronic, low-grade inflammation in adipose tissue; this can directly enhance oxidative stress [5]. Further, obesity has been associated with decreased DNA repair processes that are essential cell responses to DNA damage [6, 7], and shorter telomere length $[8,9]$.

Dietary caloric restriction (while maintaining adequate nutrition) is the only behavioral intervention able to extend lifespan in model organisms - ranging from yeast to mammals while concurrently protecting against the decline of biological function and reducing the risk of several age-related diseases [10]. The biological mechanisms underlying the beneficial effects of caloric restriction on health outcomes have been intensively investigated and include alterations in energy metabolism, insulin sensitivity, oxidative stress/DNA repair, inflammation, and neuroendocrine processes [10].

Exercise is an important intervention to support and accelerate the process of weight loss in addition to an effective diet plan. Being physical active stimulates metabolism in a human's organism, including oxidative, inflammatory and neuroendocrinological systems [11]. Intensive physical exercise may adversely influence the balance between oxidative and antioxidative factors and, thus, cause increased levels of oxidative stress [11]. Nevertheless, several exercise-only interventions have reported a reduction of biomarkers of oxidative stress [12-15]. Thus, the evidence is not entirely consistent and suggests that there may be differences attributable to varying types of exercise interventions (e.g., duration, intensity, aerobic, anaerobic). Little is known about the differences of oxidative stress-related processes between obese and non-obese individuals.

Bariatric surgery is the most effective treatment for morbid obesity [16]. The treatment reverses obesity-associated diseases such as type 2 diabetes, hypertension, dyslipidemias, and polycystic ovary syndrome [17]. Bariatric surgery has been shown to affect biological mechanisms like inflammation and oxidative stress in adipose tissue [18-20].

Bioenteric intragastric balloon (BOP) is an alternative to the pharmacological treatment of obesity. While the endoscopic procedure is associated with less risks compared to surgery, the treatment is only temporary and the balloon needs to be removed after 6 months [21]. There are not many studies investigating the effect of BOP on biological mechanisms.

Little attention has been given to whether or not weight loss induced by either of these interventions leads to changes in markers of oxidative stress, repair of DNA damage, and telomere integrity.

\section{Material and Methods}

We conducted a systematic literature search covering literature from January 1946 to April 2017. We reviewed the existing literature of the effects of intentional weight loss interventions on markers of oxidative stress, DNA repair, and telomere length. One researcher $(\mathrm{CH})$ searched the database PubMed/Medline, using keywords: (obesity OR weight loss OR weight control OR caloric restriction) AND (oxidative stress OR DNA repair OR telomere).

At identification stage, papers were selected by reading the abstract according to the following inclusion criteria: articles written in English, prospective human weight loss intervention studies, men and non- 
Fig. 1. Preferred Reporting ltems for Systematic Reviews and MetaAnalyses Protocols (PRISMA) flow diagram [17].

Himbert et al.: Effects of Intentional Weight Loss on Markers of Oxidative Stress, DNA Repair and Telomere Length - a Systematic Review

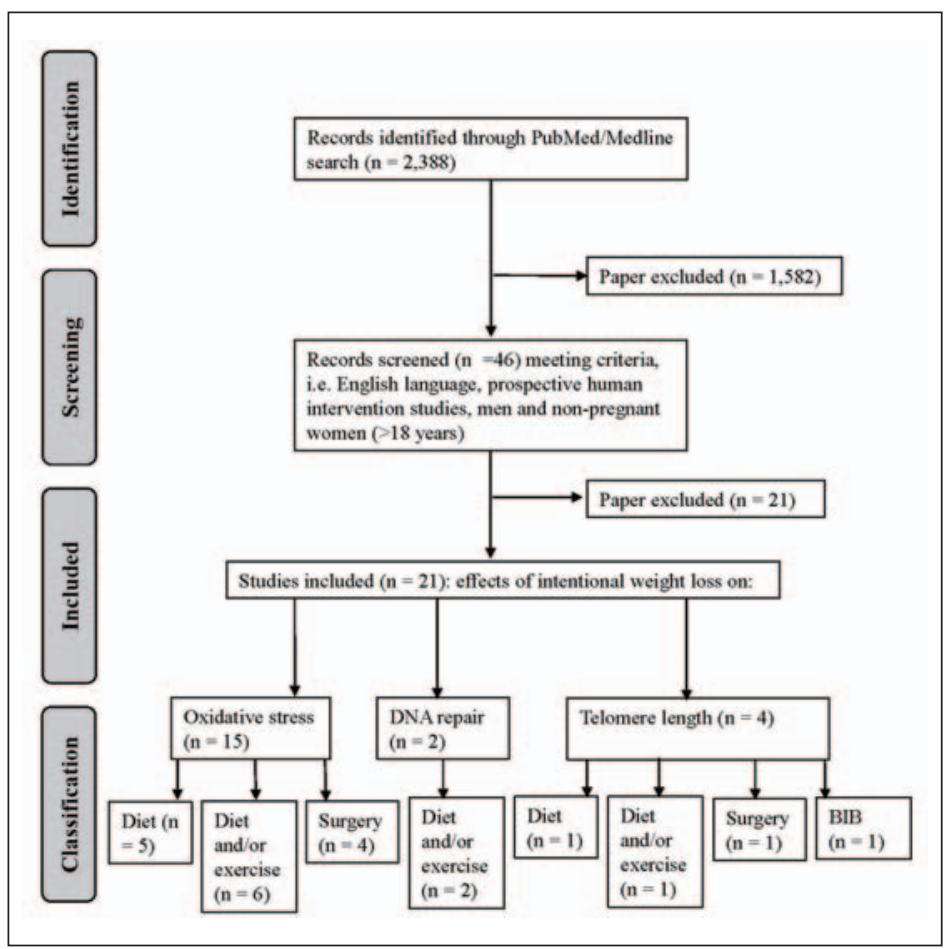

pregnant women (>18 years). At the screening stage, papers were selected using the following criteria: studies focused on the effect of diet- and/or exercise-, and surgery-induced weight loss on markers of oxidative stress, DNA repair, or telomere length.

21 out of 2,388 papers were included in this review and classified into three groups testing the effects of intentional weight loss on i) oxidative stress $(n=15)$, ii) DNA repair $(n=2)$, and iii) telomere length $(n=$ 4). Data were extracted by two authors ( $\mathrm{CH}$ and $\mathrm{CMU}$ ) in an MS Excel spreadsheet based on details on study population, BMI, intervention, randomized controlled trial (RCT, yes or no), measurement, and results. Disagreements relating to data extraction were discussed between authors and resolved. The overall process is outlined in the Preferred Reporting Items for Systematic Reviews and Meta-Analyses Protocols (PRISMA) flow diagram (fig. 1) [22].

\section{Results and Discussion}

\section{Oxidative Stress}

An imbalance between the generation of reactive oxygen species and antioxidant defenses in favor of reactive species is referred to as oxidative stress, and this phenomenon can be observed either intracellularly or systemically [23]. Reactive species are byproducts of the normal cellular metabolism of oxygen and can directly influence cell signaling and homeostasis [14]. Moreover, deregulated oxidative stress can induce toxic effects via damage of cellular structures, including proteins, lipids, and nucleic acids [24]. Damage of this type can impair cell function by affecting enzyme activities, e.g. via the inhibition of protein phosphatases and by increasing mutation rates via formation of adducts such as 8-hydroxy-2-deoxyguanosine [25]. Oxidative stress has been associated with aging and multiple age-related diseases, including cancer [26, 27], neurodegeneration [28, 29], cardiovascular disease [30, 31], and diabetes [32]. Commonly assessed markers for oxidative stress are lipid oxidation products such as 8-isoprostane and malondialdehyde, and DNA oxidation products such as 
8-hydroxy-2-deoxyguanosine (8-oxo-dG) which can be measured in blood and/or urine [33]. The activity of antioxidant enzymes, e.g., glutathione peroxidase or catalase, can also provide information regarding oxidative stress [34]. While multiple biomarkers have been developed that measure various types of oxidative stress, there are unresolved challenges in devising accurate and reproducible assays that can be applied to human studies [24,25].

We identified 15 studies investigating the effect of weight loss interventions (diet-and/ or exercise-, and surgery-induced) on individuals' oxidative stress level (table 1): 6 RCTs and 9 non-randomized intervention studies $(\mathrm{n}=5$ diet, $\mathrm{n}=6$ diet and/or exercise interventions, and $n=3$ bariatric surgery interventions) [35-48]. All studies measured oxidative stress markers in blood samples (plasma or serum, e.g., enzyme activities, 8-isoprostane, 8-oxo-dG; for details see table 1) [35-48].

\section{Diet-Induced Weight Loss}

A double-crossover, double-blind RCT of intermittent fasting was recently conducted among 24 healthy individuals (BMI $20-30 \mathrm{~kg} / \mathrm{m}^{2}$ ) [39]. Study participants were subject to two 3-week treatment periods, separated into intermittent fasting and intermittent fasting with anti-oxidant supplementation (vitamins C and E) [39]. Although the study participants showed excellent adherence to the study-provided diets, only a marginal increase $(2.7 \%)$ in SIRT3 expression was observed, with no change in the expression of other genes or biomarkers of oxidative stress [39].

Another study recruited 122 overweight/obese participants $\left(25 \leq \mathrm{BMI}<34 \mathrm{~kg} / \mathrm{m}^{2}\right.$, 30-59 years) into a 3-year-long study, testing the effects of a clinical intervention with daily 100 -kcal calorie deficits [36]. They distinguished the participants as 'successful mild weight loss group' (SWL), with an average body weight reduction of $5.4 \%(-4.16 \pm 0.31 \mathrm{~kg}), \mathrm{n}=50$, compared to an 'unsuccessful group' $(0.05 \pm 0.14 \mathrm{~kg}), \mathrm{n}=49$ [36]. The SWL group showed significant decreases in insulin, triglycerides, total and low-density lipoprotein cholesterol, free fatty acids, and leukocyte count $(\mathrm{p}=0.030)$ [36]. Further, SWL participants experienced reduced serum interleukin(IL)-1 $\beta$, IL-6, and urinary 8 -isoprostane $(45 \%, 30 \%$, and $14 \%$, respectively) [36]. Statistically significant group differences were seen for percentage of body fat, waist circumference, leukocyte count ( $p=0.018)$, insulin, IL-6 ( $p=0.031)$, IL-1 $\beta(p<$ $0.001)$, tumor necrosis factor- $\alpha(p<0.001)$, and urinary 8-isoprostane $(p=0.036)$ [36]. A positive association was observed between IL-1 $\beta$ and urinary 8-isoprostane $(r=0.44, p<$ $0.001)$ as well as between changes in IL-6 and urinary 8-isoprostane ( $r=0.39, p<0.001)$ [36].

Buchowski et al. [35] initiated a RCT testing the effects of $25 \%$ caloric restriction or control diet on oxidative stress markers in 40 overweight or obese women, with direct observation for 28 days and follow-up for the next 90 days. At study outset, the median 8-isoprostane concentration $(57.0 \mathrm{pg} / \mathrm{ml}$, interquartile range $(\mathrm{IQR})=40.5-79.5 \mathrm{pg} / \mathrm{ml})$ in the caloric restriction group was 1.75-fold times that of the concentration observed in normal-weight women $(32.5 \mathrm{pg} / \mathrm{ml})$ [35]. During caloric restriction, 8-isoprostane levels were reduced, resulting in statistically significant differences from the control group by day 5 (median 33.5 $\mathrm{pg} / \mathrm{ml}, \mathrm{IQR}=26.0-48.0 \mathrm{pg} / \mathrm{ml} ; \mathrm{p}<0.001$ ) [35]. While the women continued on the caloric restriction diet, concentrations remained low [35]. However, after 3 months on their habitual diet, they returned to baseline levels in about $80 \%$ of the women. The authors concluded that oxidative stress levels may be rapidly decreased and maintained through a modest reduction in caloric intake [35].

Meydani et al. [38] conducted a controlled feeding study among 46 moderately overweight volunteers (BMI $25-30 \mathrm{~kg} / \mathrm{m}^{2}$, age 20-42 years). They were randomized to a 6-month high-glycemic (HG) or low-glycemic (LG) dietary load caloric restriction regimen at either $10 \%(n=12)$ or $30 \%(n=34)$ of basal caloric intake. Independent of the intervention arm, plasma glutathione peroxidase activity increased $(p=0.04)$ and plasma protein carbonyl 
Himbert et al.: Effects of Intentional Weight Loss on Markers of Oxidative Stress, DNA Repair and Telomere Length - a Systematic Review

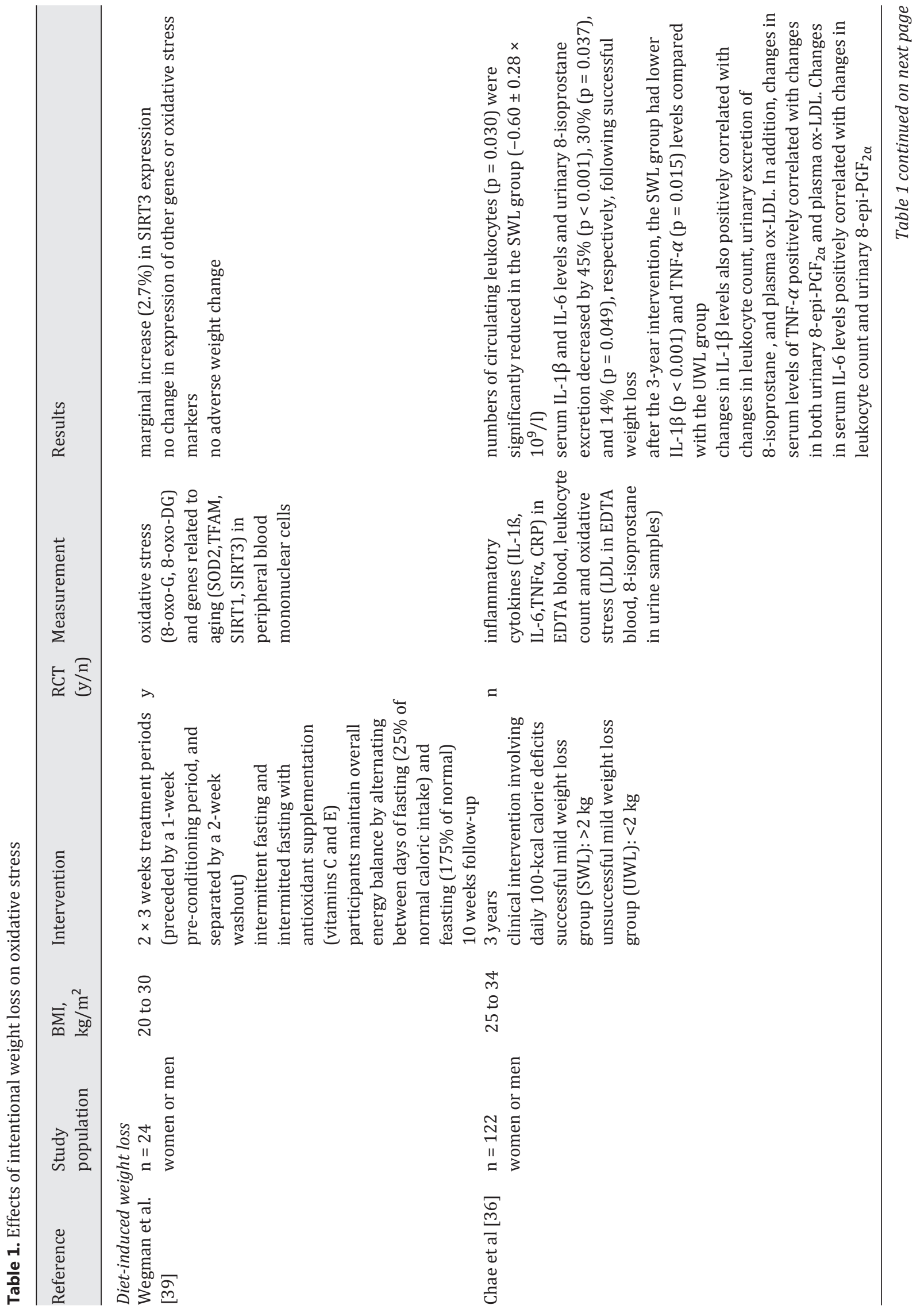


Himbert et al.: Effects of Intentional Weight Loss on Markers of Oxidative Stress, DNA Repair and Telomere Length - a Systematic Review

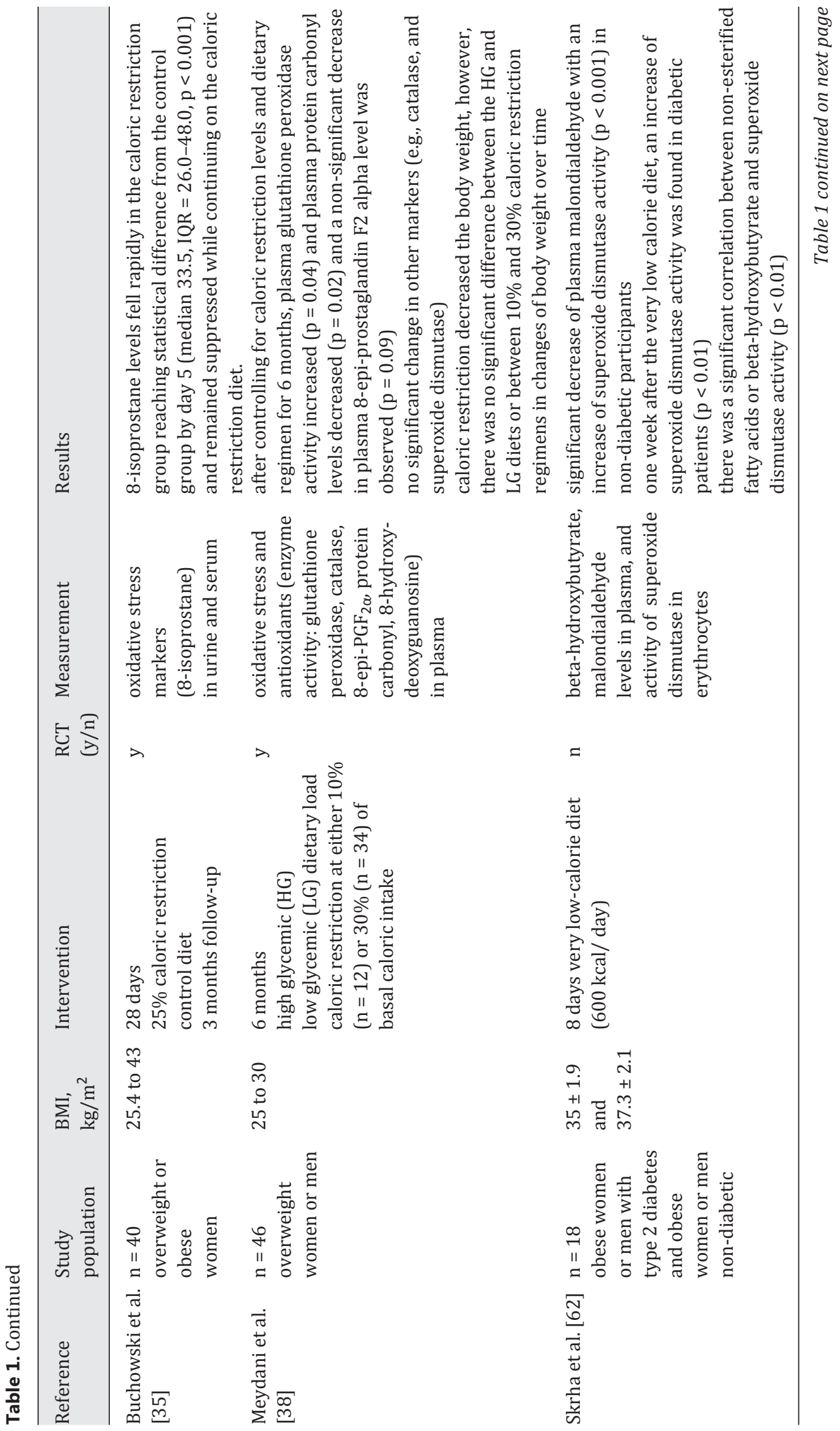


Himbert et al.: Effects of Intentional Weight Loss on Markers of Oxidative Stress, DNA Repair and Telomere Length - a Systematic Review

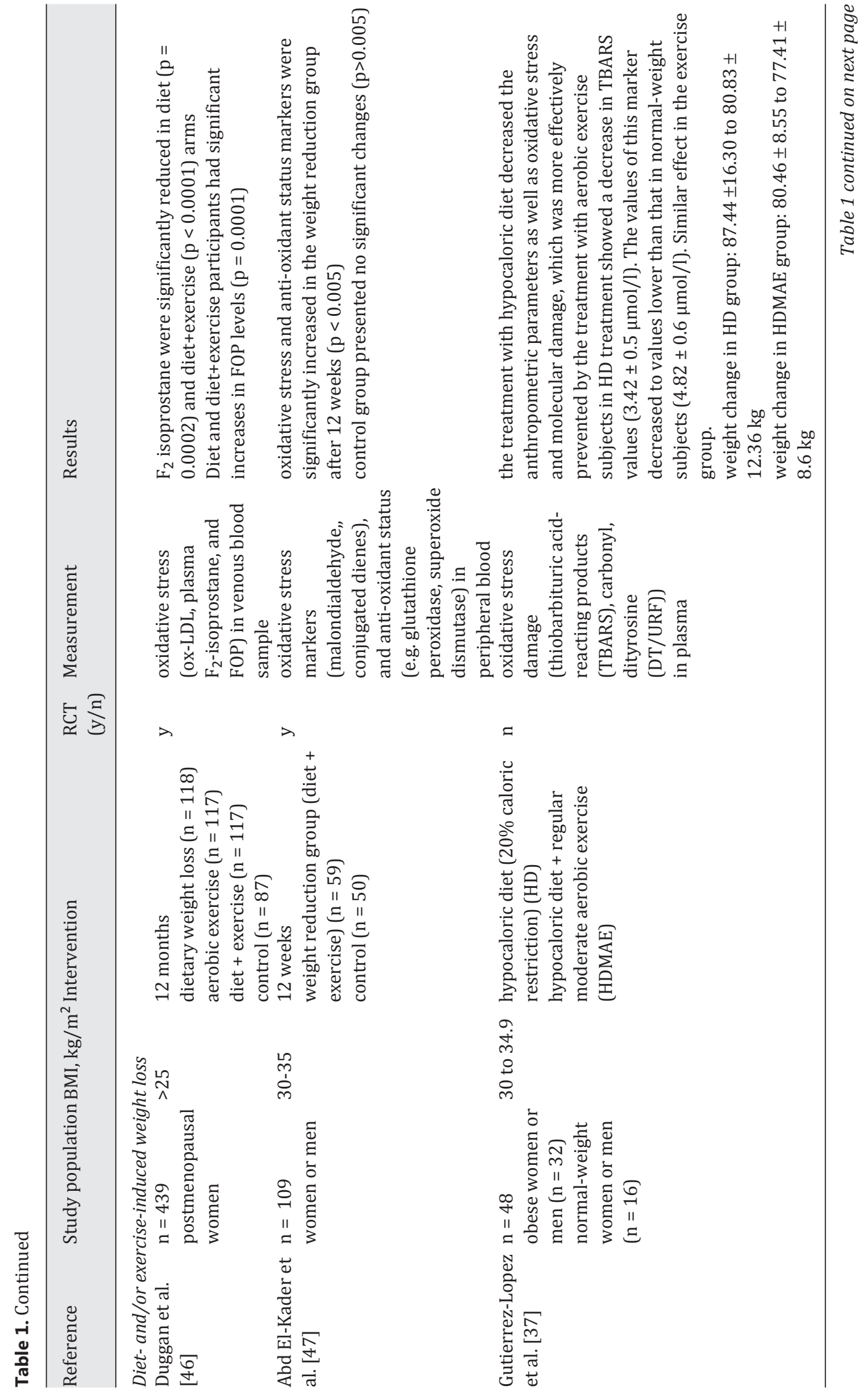


Himbert et al.: Effects of Intentional Weight Loss on Markers of Oxidative Stress, DNA

Repair and Telomere Length - a Systematic Review

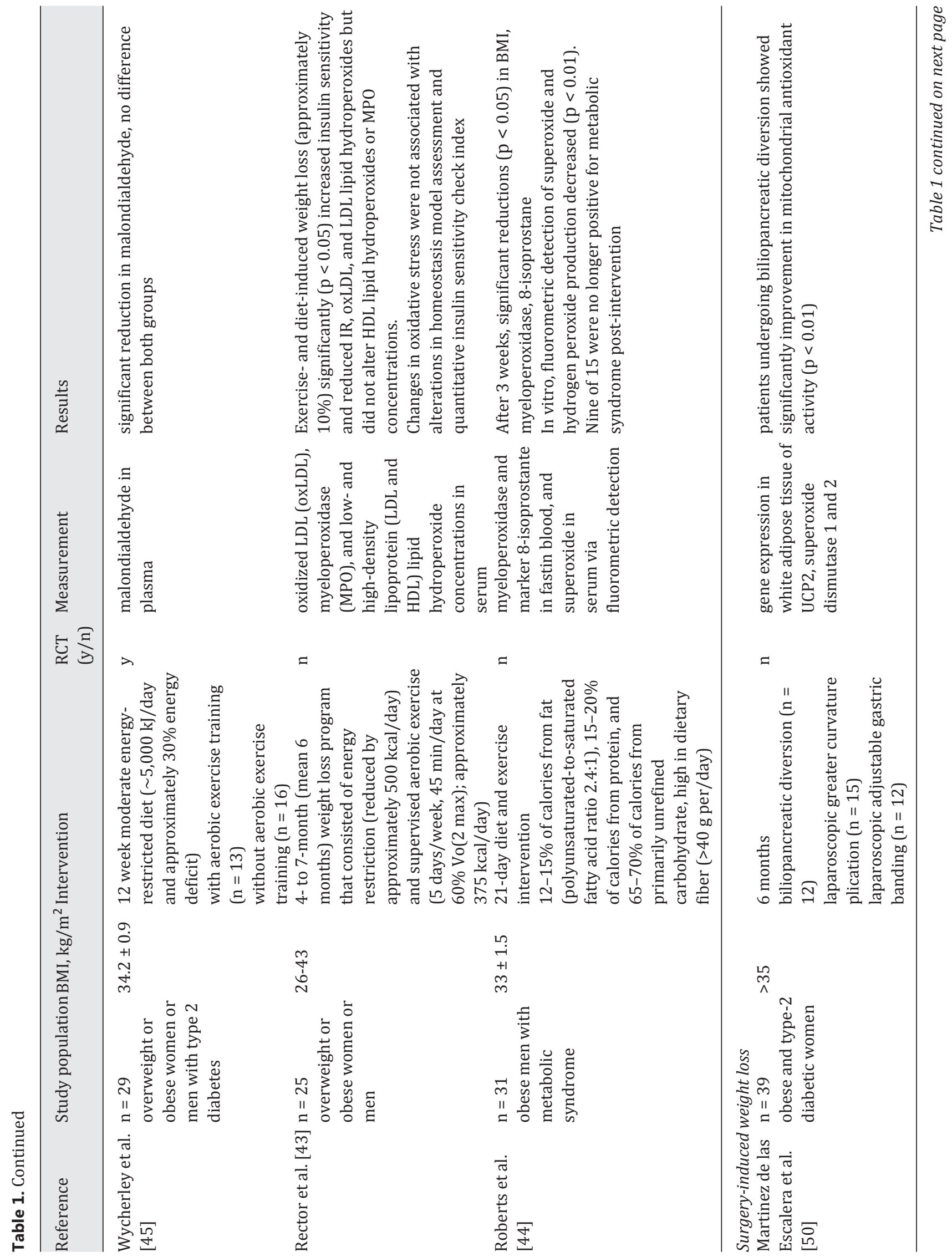


Himbert et al.: Effects of Intentional Weight Loss on Markers of Oxidative Stress, DNA Repair and Telomere Length - a Systematic Review

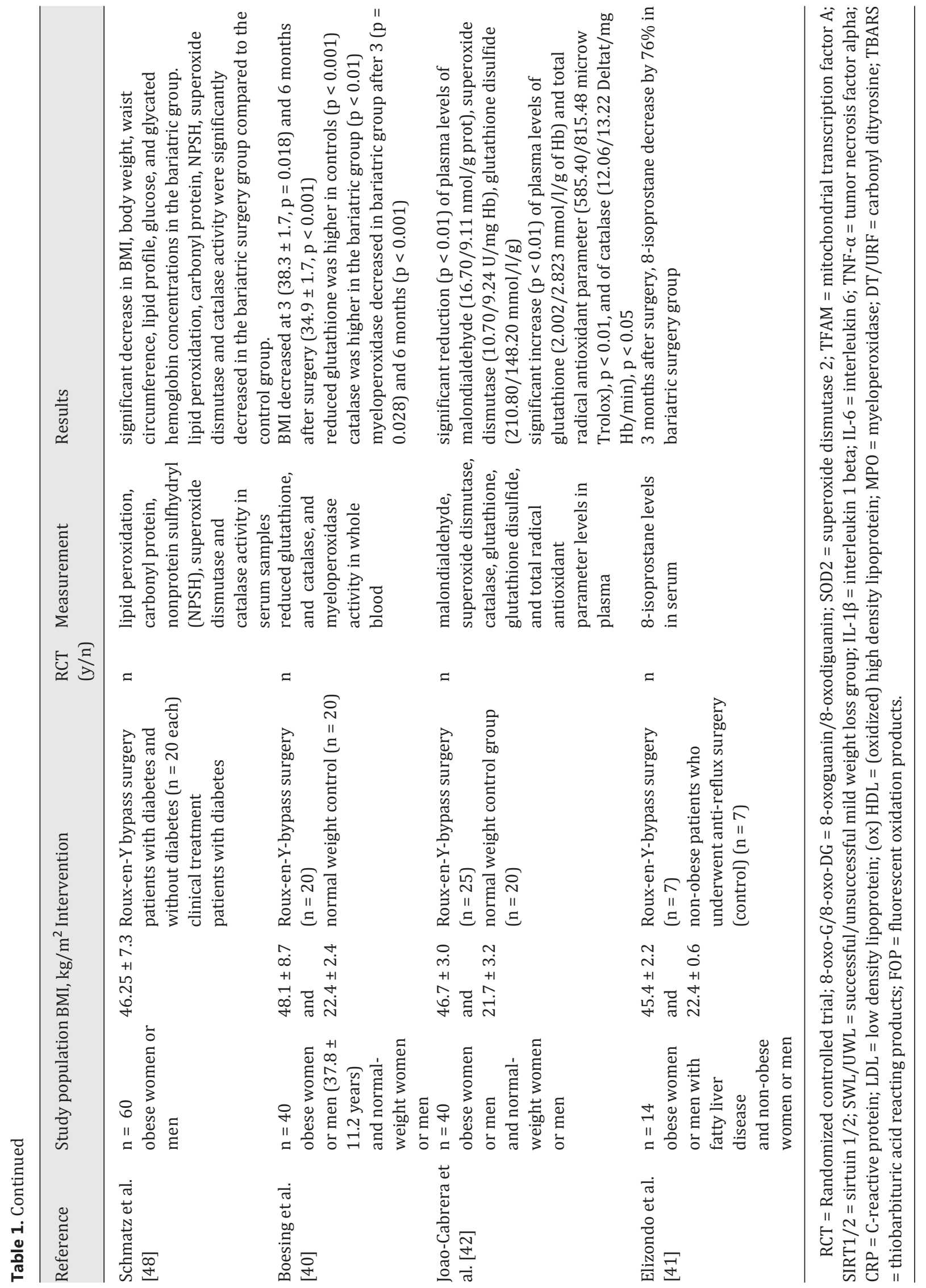


levels declined $(\mathrm{p}=0.02)$ [38]. Concomitantly, plasma 8-isoprostane levels decreased nonsignificantly $(\mathrm{p}=0.09)$, and no changes in superoxide dismutase and catalase activity were observed [38].

Diet- and/or Exercise-Induced Weight Loss

The Nutrition and Exercise in Women (NEW) study, recruited 439 postmenopausal women with BMI over $25 \mathrm{~kg} / \mathrm{m}^{2}$ who were randomized into four groups: i) dietary weight loss, ii) aerobic exercise, iii) diet + exercise, or iv) control [46]. The diet intervention was a group-based program aiming for a $10 \%$ weight loss [46]. The exercise intervention consisted of $45 \mathrm{~min} /$ day, 5 days/week moderate-to-vigorous aerobic activity [46]. Fasting blood samples were obtained at baseline and after 12 months [46]. Markers of oxidative stress were analyzed including oxidized low-density lipoprotein (oxLDL), plasma F2-isoprostane, and fluorescent oxidation products (FOP) [46]. Diet, either with or without exercise intervention, resulted in a significant increase of LDL and F2-isoprostane ( $p=0.0002, p<0.0001)$ and a decrease of FOP ( $p=0.0001)$ [46] while the exercise group showed no statistically significant effects $(p=0.01)$ [46]. However, the exercise group did not experience as much weight loss $(-2.4 \% ; \mathrm{p}<0.03)$ as the $\operatorname{diet}(-8.5 \%)$ and the diet + exercise group $(-10.8 \%)$, which may be one explanation for the different results.

Another recent study focused on obese type 2 diabetes patients, given that type 2 diabetes is associated with irregular inflammatory or oxidative stress-related biomarkers [47]. 80 patients were randomized into either weight reduction (low-calorie diet and aerobic exercise training) or control group [47]. After 12 weeks the weight reduction group showed significantly reduced levels of oxidative stress-related markers $(\mathrm{p}<0.005$; e.g., malondialdehyde, glutathione peroxidase, superoxide dismutase, glutathione), while levels of the control group did not change [47].

Gutierrez-Lopez et al. [37] recruited 16 normal-weight and 32 obese subjects (BMI $30-34.9 \mathrm{~kg} / \mathrm{m}^{2}$ ) into a non-randomized intervention study testing the effects of a hypocaloric diet and hypocaloric diet plus regular moderate aerobic exercise intervention on oxidative stress. At baseline, obese study participants had greater oxidative stress markers as well as increased molecular damage and polymerization of insulin. The hypocaloric diet intervention resulted in reduced oxidative stress and decreased molecular damage. The oxidative stress levels improved even more with the combined diet and exercise intervention [37].

Wycherley et al. [45] conducted another study that compared a diet intervention with and without aerobic exercise training in overweight and obese subjects with type 2 diabetes. The 12-week intervention lead to a significant reduction of malondialdehyde ( $p \leq 0.05)$ and an increase of urinary nitrite/nitrate $(p<0.01)$ in both groups [45]. The total antioxidant capacity slightly increased with both interventions $(p<0.08)$ [45]. Both interventions induced a comparable weight reduction of $8.5-8.9 \%$. If weight loss enhances effects on oxidative stress, this may explain the lack of a difference.

Surgery-Induced Weight Loss

As the most effective treatment, bariatric surgery is the gold standard for the treatment of severe obesity [16]. Since the first steps in the 1950s, the number of patients undergoing bariatric surgery have followed similar trends as the incidence of obesity [49], and the research on post-surgery outcomes and complications has increased. Even prior to significant weight loss, the surgical treatment reverses metabolic syndrome-related diseases, such as type 2 diabetes, hypertension, dyslipidemias, polycystic ovary syndrome, and non-alcoholic steatosis hepatitis [17]. While insulin levels return back to normal rates within days after bariatric surgery, it takes many months to recover insulin resistance as well as inflammation 
and oxidative stress in adipose tissue [18-20]. Five studies have focused on the effect of bariatric surgery on oxidative stress [40-42, 48,50].

One recent study was conducted in 60 obese women and men [48]. 40 patients $(n=20$ diabetic, $\mathrm{n}=20$ non-diabetic) underwent bariatric surgery, and 20 patients received clinical treatment [48]. Compared to pre-surgery, the bariatric surgery group showed a significant reduction in levels of lipid peroxidation, carbonyl protein, and non-protein sulfhydryl, as well as in superoxide dismutase and catalase activity [48]. Further, they observed a significant decrease of inflammatory biomarkers including IL-6, IL-1, and tumor necrosis factor-alpha [48].

In another study in 20 obese women or men undergoing bariatric surgery were compared with 20 normal-weight controls [40]. Reduced glutathione and activity of catalase and myeloperoxidase were measured in blood samples [40]. At 6 months, the bariatric groups showed higher catalase activity $(\mathrm{p}<0.01)$ compared to controls [40]. In addition, myeloperoxidase decreased in the bariatric group after $3(p=0.028)$ and 6 months post-surgery $(p<0.001)$ [40].

Following the same study design, Joao-Cabrera et al. [42], measured in addition different markers of oxidative stress in plasma (e.g. malondialdehyde, superoxide dismutase, catalase, and total radical antioxidant parameter). A significant reduction 12 months post-surgery ( $\mathrm{p}$ $<0.01$ ) could be detected in malondialdehyde, superoxide dismutase as well as in glutathione disulfide [42]. In contrast, plasma levels of glutathione and total radical antioxidant parameters showed a significant increase $(p<0.01)$ [42]. In a smaller population of 14 participants, including an intervention $(n=7)$ and a control $(n=7)$ group, a decrease of 8-isoprostane by $75 \%$ was reported 3 months post-surgery [41].

Only one study investigated the effects of different bariatric surgical procedures on oxidative stress [50]. Using quantitative real-time polymerase chain reaction (PCR), they analyzed the expression of various genes in mitochondria of white adipose tissue samples of 39 obese and diabetic women [50]. Their results showed a significant improvement of antioxidant-related gene expression (e.g., UCP2, SOD1 and SOD2) in patients undergoing the malabsorptive procedure of the biliopancreatic diversion compared to the restrictive procedure (laparoscopic adjustable gastric banding and laparoscopic greater curvature plication) [50].

\section{DNA Repair}

Repair mechanisms are essential cell responses to DNA damage, and defects can accelerate aging processes and aggravate chronic diseases [51]. In experimental models, DNA repair deficiency has been linked to central characteristics of the metabolic syndrome: severe obesity, fatty liver disease, dyslipidemia, and insulin resistance [6, 7].

At least four types of DNA repair mechanisms need to be considered: i) base-excision repair, ii) nucleotide-excision repair, iii) mismatch repair, and iv) double-strand-break repair [52]. Dysfunction of DNA repair mechanisms can be assessed by measuring DNA damage using, e.g., PCR or fluorescence in situ hybridization (FISH), and by directly measuring DNA repair capacity, e.g., by single cell gel electrophoresis (COMET) assay [52]. In addition, genomic instability, which may be caused by DNA repair defects, is considered an evolving hallmark of cancer [53]. Our systematic literature search identified only two RCTs focusing on the effect of diet- and/or exercise-induced intentional weight loss on DNA repair capacity (table 2) $[54,55]$. No parallel study was identified evaluating the effects of surgery-induced weight loss.

Habermann et al. [54] evaluated the effects of the independent and combined weight loss interventions on DNA repair capacity analyzing data from the NEW study (study design see above). They applied a modified COMET assay using cryopreserved lymphocytes from the 
Himbert et al.: Effects of Intentional Weight Loss on Markers of Oxidative Stress, DNA

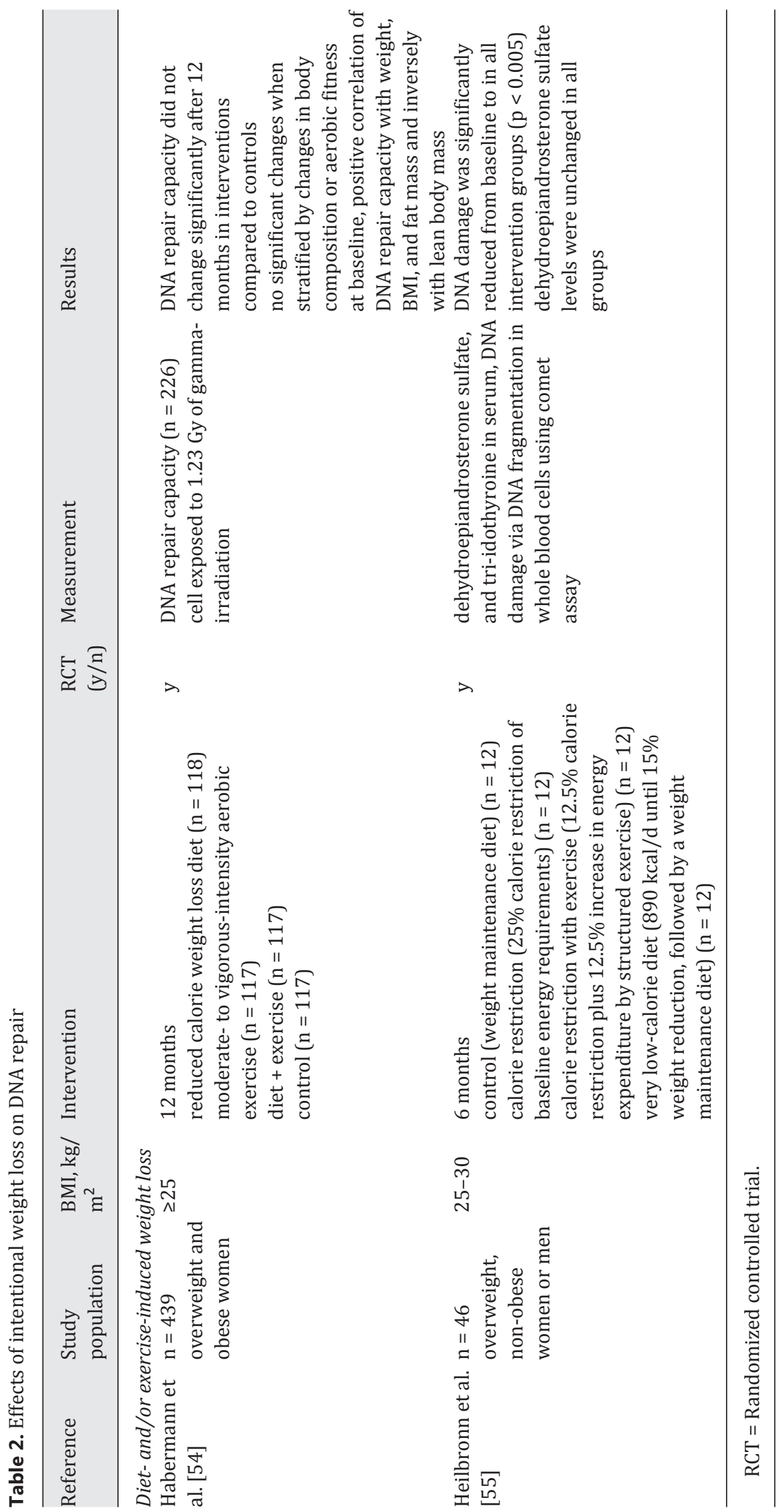


pre- and post-intervention time points that were analyzed within the same batch [54]. DNA repair capacity did not change significantly as a result of any of the diet or exercise interventions compared to control; further, there were no significant changes when results were stratified by changes in body composition or aerobic fitness (VO2max) [54].

In 2006, an RCT investigated whether a calorie restriction alone or in combination with an increased energy expenditure affects DNA damage [55]. Participants were randomly assigned to one out of four groups including control, calorie restriction ( $25 \%$ diet restriction), calorie restriction and exercise $(12.5 \%$ diet restriction, $12.5 \%$ increase in energy expenditure), and low-calorie diet until 15\% weight reduction followed by weight maintenance [55]. DNA damage was measured via COMET assay using whole blood cells [55]. After the 6-month intervention, DNA damage was significantly reduced in all three weight loss intervention groups compared to the control group [55].

\section{Telomere Length}

Telomeres are the specific DNA-protein structures that are found at both ends of each chromosome and protect the genome from nucleolytic degradation, unnecessary recombination, repair, and interchromosomal fusion [56]. The enzyme telomerase, which elongates telomeres and thus ensures telomere integrity, is central for a cell's ability to replicate without limit, a hallmark of carcinogenesis [57]. Telomeres shorten with age or with replicative cycles, and shortening has been associated with inflammatory processes [58]. Increased shortening leads to senescence, apoptosis, or oncogenic transformation of somatic cells , affecting the health and aging of an individual [56]. Changes in telomere length are generally assessed in blood samples by extracting cellular DNA.

A number of investigations have reported that obesity is associated with shorter telomere length in varying cell types [8, 9]. A recent meta-analysis and systematic review comprising 119,439 individuals reported that 39 studies presented weak to moderate correlations between obesity and telomere length [59]. However, they also saw significant methodological, clinical, and statistical heterogeneity between studies, which suggests that this association needs to be better defined and additional causative factors must be taken into account [59]. The effect of intentional weight loss on telomere length has been studied in two RCTs and two non-randomized intervention studies (table 3) [8, 9, 60, 61].

Diet-Induced Weight Loss

Garcia-Calzon et al. [9] reported in 2014 that a 2-month energy-restricted diet (30\% of energy from fat, $15 \%$ energy from proteins, and 55\% energy from carbohydrates) based on their glycemic index resulted in increased telomere length among 12- to 16-year-old obese adolescents, with a greater effect in overweight/obese adolescents who had the shortest telomeres at baseline $(r=0.96 ; p<0.001)$ [9].

Diet- and/or Exercise-Induced Weight Loss

The NEW study (study design see above), also tested the effects of the diet/exercise interventions on leukocyte telomere length [8]. DNA was extracted from isolated leukocytes, and quantitative PCR) was used to measure telomere length. Baseline telomere length was moderately inversely associated with age $(\mathrm{r}=-0.12 ; \mathrm{p}<0.01)$ and moderately positively with maximal oxygen uptake, a measure of fitness, $(r=0.11 ; \mathrm{p}=0.03)$, but not with BMI or percent body fat [8]. After the interventions, change in telomere length was inversely associated with telomere length at baseline $(r=-0.47 ; p<0.0001)$ [8]. The independent and combined diet/ exercise interventions did not result in any significant group differences in leukocyte telomere length compared to controls. Further, the authors observed no differences in telomere length by the degree of weight loss [8]. 
Himbert et al.: Effects of Intentional Weight Loss on Markers of Oxidative Stress, DNA

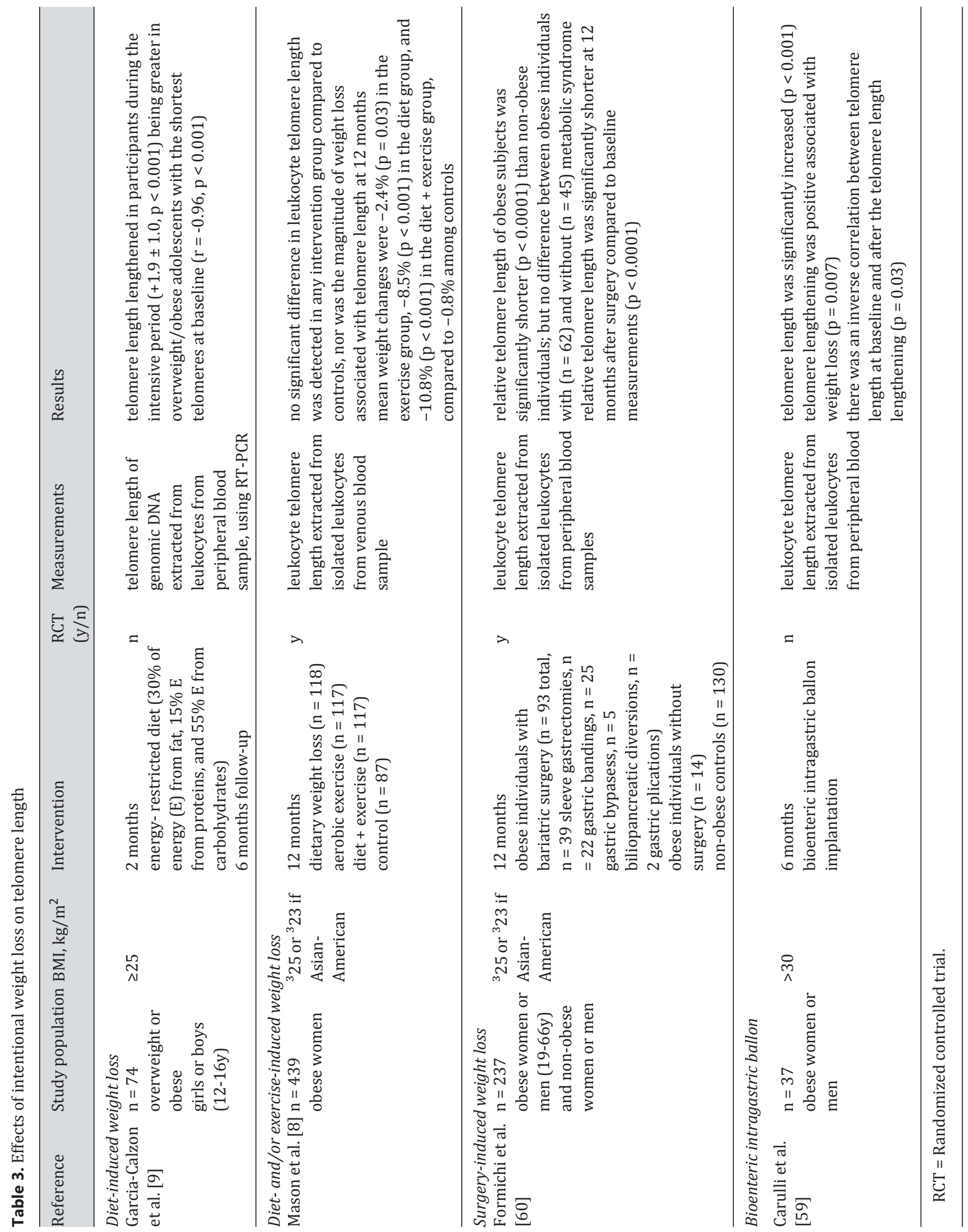


Himbert et al.: Effects of Intentional Weight Loss on Markers of Oxidative Stress, DNA Repair and Telomere Length - a Systematic Review

Surgery-Induced Weight Loss

Formichi et al. [60] have conducted the only surgery-induced non-randomized intervention study focusing on the patients' telomere length up to 12 months post-surgery. 237 individuals were recruited (130 non-obese individuals 107 obese individuals). 93 of the 107 obese participants underwent bariatric surgery treatment [60]. Findings support the results of diet-induced interventions, reporting that the telomere length of obese participants was significantly shorter $(p<0.0001)$ [60]. Moreover, the obese group has been divided into individuals with $(n=62)$ and without $(n=45)$ metabolic syndrome, and measurements showed that there was no difference in the telomere length between both groups [60]. 12 months post-surgery, the 93 individuals in the bariatric surgery group had significantly shorter telomere length compared to baseline $(\mathrm{p}<0.0001)$ [60].

Bioenteric Intragastric Balloon (BOP)

To date, Carulli et al. [59] performed the only study that has investigated the effect of the BOP procedure on telomere length. Blood samples from 37 obese individuals undergoing BOP as weight loss intervention were analyzed [59]. All participants showed a significant increase in telomere length $(p<0.001)$ [59]. Telomere lengthening was positively associated with weight loss ( $p=0.007)$, and an inverse association was observed between telomere length at baseline and lengthening $(\mathrm{p}=0.003)$ [59].

\section{Conclusions}

Oxidative stress, DNA repair, and telomere maintenance are processes that have been linked to aging as well as to multiple chronic diseases. Their association with obesity is strong to moderate [5-9]. In animal studies, caloric restriction has been shown to be effective in reducing oxidative stress and increasing DNA repair capacity. Thus, a key question is whether intentional weight loss among the obese or overweight (either through dietary restriction, dietary restriction and exercise, bariatric surgery or BOP) may have similar effects and positively impact these biologic mechanisms or associated biomarkers.

Intentional weight loss, either through diet, exercise or bariatric surgery, reduced oxidative stress in obese individuals as evidenced by decreased levels of 8-isoprostane and malondialdehyde and increased activity of anti-oxidant enzymes, whereas contrary effects on DNA repair capacity were observed. In some respect, the lack of impact on DNA repair is anticipated since the level of oxidative stress was decreased by intentional weight loss. However, given that assay limitations were reported in one of the two RCTs addressing this question in obese subjects, further investigation is required.

Telomere maintenance is directly linked to aging and immortalization, a hallmark of cancer. Obesity has been quite consistently linked to shorter telomere length. However, the evidence in support of improvement with intentional weight loss through diet, surgery, or BOP was inconsistent and highlights the need for a re-assessment of the intervention designs and assay methodology required to definitively address this topic.

A limited number of studies compared the effects of diet-, exercise-, and combined dietexercise interventions. Only one study included an exercise-only group in their study design, which seemed to have no effects on levels of oxidative stress, in contrast to prior reports on exercise-only interventions [12-15]. Combined diet- and exercise-induced weight loss interventions may achieve an additional benefit with respect to oxidative stress, DNA repair, and telomere length. Further studies, however, are needed to investigate whether the type of intervention (diet, exercise, or combined) is critical to affect a significant change of levels of oxidative stress, DNA repair, and telomere length and to what extent weight loss is central. 
Different bariatric surgery procedures can have differential impact on a human's metabolism, which may affect malabsorption of various important metabolites. One study reported that the improvement in oxidative stress and, thus, the mitochondrial health of white adipose tissue may differ between surgical procedures [50], suggesting that malabsorptive procedures (e.g., biliopancreatic diversion) are associated with better metabolic outcomes than restrictive bariatric surgery (e.g., sleeve gastrectomy). Formichi et al. [60], however, did not observe any differences between surgery procedures regarding effects on telomere length. Because of the recognition that malabsorptive and restrictive procedures have a significantly different impact on metabolism, future studies should explore their different effects on oxidative stress, DNA repair, and telomere length.

\section{Acknowledgments}

C. Himbert is sponsored by the Stiftung LebensBlicke and Claussen-Simon-Stiftung, Germany.

C. Himbert and C. Ulrich are funded by the Huntsman Cancer Foundation, and C. Ulrich also by R01CA189184 and U01CA2061.

\section{Disclosure Statement}

The authors declare that there is no conflict of interest regarding the publication of this paper.

\section{References}

1 World Obesity Federation: Obesity Prevalence Worldwide - Adults. www.worldobesity.org/data/map/ overview-adults (last accessed November 28, 2017)

2 Ogden CL, Carroll MD, Kit BK, Flegal KM: Prevalence of childhood and adult obesity in the United States, 20112012. JAMA 2014;311:806-814.

3 Martin-Rodriguez E, Guillen-Grima F, Marti A, Brugos-Larumbe A: Comorbidity associated with obesity in a large population: the APNA study. Obes Res Clin Pract 2015;9:435-447.

4 Lauby-Secretan B, Scoccianti C, Loomis D, Grosse Y, Bianchini F, Straif K, International Agency for Research on Cancer Handbook Working G: Body Fatness and Cancer - Viewpoint of the IARC Working Group. N Engl J Med 2016;375:794-798.

5 Marseglia L, Manti S, D’Angelo G, Nicotera A, Parisi E, Di Rosa G, Gitto E, Arrigo T: Oxidative stress in obesity: a critical component in human diseases. Int J Mol Sci 2015;16:378-400.

6 Sampath H, Batra AK, Vartanian V, Carmical JR, Prusak D, King IB, Lowell B, Earley LF, Wood TG, Marks DL, McCullough AK, L RS: Variable penetrance of metabolic phenotypes and development of high-fat diet-induced adiposity in NEIL1-deficient mice. Am J Physiol Endocrinol Metab 2011;300:E724-734.

7 Vartanian V, Lowell B, Minko IG, Wood TG, Ceci JD, George S, Ballinger SW, Corless CL, McCullough AK, Lloyd RS: The metabolic syndrome resulting from a knockout of the NEIL1 DNA glycosylase. Proc Natl Acad Sci U S A 2006;103:1864-1869.

8 Mason C, Risques RA, Xiao L, Duggan CR, Imayama I, Campbell KL, Kong A, Foster-Schubert KE, Wang CY, Alfano CM, Blackburn GL, Rabinovitch PS, McTiernan A: Independent and combined effects of dietary weight loss and exercise on leukocyte telomere length in postmenopausal women. Obesity (Silver Spring) 2013; 21::E549-554.

9 Garcia-Calzon S, Moleres A, Marcos A, Campoy C, Moreno LA, Azcona-Sanjulian MC, Martinez-Gonzalez MA, Martinez JA, Zalba G, Marti A: Telomere length as a biomarker for adiposity changes after a multidisciplinary intervention in overweight/obese adolescents: the EVASYON study. PloS One 2014;9:e89828.

10 Minor RK, Allard JS, Younts CM, Ward TM, de Cabo R: Dietary interventions to extend life span and health span based on calorie restriction. J Gerontol A Biol Sci Med Sci 2010;65:695-703.

11 Slattery K, Bentley D, Coutts AJ: The role of oxidative, inflammatory and neuroendocrinological systems during exercise stress in athletes: implications of antioxidant supplementation on physiological adaptation during intensified physical training. Sports Med 2015;45:453-471.

12 Sarifakioglu B, Guzelant AY, Guzel EC, Guzel S, Kiziler AR: Effects of 12-week combined exercise therapy on oxidative stress in female fibromyalgia patients. Rheumatol Int 2014;34:1361-1367.

13 Campbell PT, Gross MD, Potter JD, Schmitz KH, Duggan C, McTiernan A, Ulrich CM: Effect of exercise on oxidative stress: a 12-month randomized, controlled trial. Med Sci Sports Exerc 2010;42:1448-1453. 
Himbert et al.: Effects of Intentional Weight Loss on Markers of Oxidative Stress, DNA Repair and Telomere Length - a Systematic Review

14 Laufs U, Wassmann S, Czech T, Munzel T, Eisenhauer M, Bohm M, Nickenig G: Physical inactivity increases oxidative stress, endothelial dysfunction, and atherosclerosis. Arterioscler Thromb Vasc Biol 2005;25:809814.

15 Arikawa AY, Thomas W, Gross M, Smith A, Phipps WR, Kurzer MS, Schmitz KH: Aerobic training reduces systemic oxidative stress in young women with elevated levels of F2-isoprostanes. Contemp Clin Trials 2013; 34:212-217.

16 Powell MS, Fernandez AZ Jr: Surgical treatment for morbid obesity: the laparoscopic Roux-en-Y gastric bypass. Surg Clin North Am 2011;91:1203-1224, viii.

17 Xu XJ, Pories WJ, Dohm LG, Ruderman NB: What distinguishes adipose tissue of severely obese humans who are insulin sensitive and resistant? Curr Opin Lipidol 2013;24:49-56.

18 Illan-Gomez F, Gonzalvez-Ortega M, Orea-Soler I, Alcaraz-Tafalla MS, Aragon-Alonso A, Pascual-Diaz M, PerezParedes M, Lozano-Almela ML: Obesity and inflammation: change in adiponectin, C-reactive protein, tumour necrosis factor-alpha and interleukin-6 after bariatric surgery. Obes Surg 2012;22:950-955.

19 Kelly AS, Ryder JR, Marlatt KL, Rudser KD, Jenkins T, Inge TH: Changes in inflammation, oxidative stress and adipokines following bariatric surgery among adolescents with severe obesity. Int J Obes 2016;40:275-280.

20 Gletsu-Miller N, Hansen JM, Jones DP, Go YM, Torres WE, Ziegler TR, Lin E: Loss of total and visceral adipose tissue mass predicts decreases in oxidative stress after weight-loss surgery. Obesity (Silver Spring) 2009;17: 439-446.

21 Kim SH, Chun HJ, Choi HS, Kim ES, Keum B, Jeen YT: Current status of intragastric balloon for obesity treatment. World J Gastroenterol 2016;22:5495-5504.

22 Moher D, Shamseer L, Clarke M, Ghersi D, Liberati A, Petticrew M, Shekelle P, Stewart LA: Preferred reporting items for systematic review and meta-analysis protocols (PRISMA-P) 2015 statement. Syst Rev 2015;4:1.

23 Sies H: Oxidative stress: a concept in redox biology and medicine. Redox Biol 2015;4:180-183.

24 Poli G, Leonarduzzi G, Biasi F, Chiarpotto E: Oxidative stress and cell signalling. Curr Med Chem 2004;11: 1163-1182.

25 Nakabeppu Y, Sakumi K, Sakamoto K, Tsuchimoto D, Tsuzuki T, Nakatsu Y: Mutagenesis and carcinogenesis caused by the oxidation of nucleic acids. Biol Chem 2006;387:373-379.

26 Sung HJ, Ma W, Starost MF, Lago CU, Lim PK, Sack MN, Kang JG, Wang PY, Hwang PM: Ambient oxygen promotes tumorigenesis. PloS One 2011;6:e19785.

27 Valko M, Rhodes CJ, Moncol J, Izakovic M, Mazur M: Free radicals, metals and antioxidants in oxidative stressinduced cancer. Chem Biol Interact 2006;160:1-40.

28 Andersen JK: Oxidative stress in neurodegeneration: cause or consequence? Nat Med 2004;10(suppl):S18-25.

29 Halliwell B: Oxidative stress and neurodegeneration: where are we now? J Neurochem 2006;97:1634-1658.

30 Dhalla NS, Temsah RM, Netticadan T: Role of oxidative stress in cardiovascular diseases. J Hypertens 2000;18: 655-673.

31 Griendling KK, FitzGerald GA: Oxidative stress and cardiovascular injury: Part II: animal and human studies. Circulation 2003;108:2034-2040.

32 Ceriello A, Motz E: Is oxidative stress the pathogenic mechanism underlying insulin resistance, diabetes, and cardiovascular disease? The common soil hypothesis revisited. Arterioscler Thromb Vasc Biol 2004;24:816823.

33 Dreissigacker U, Suchy MT, Maassen N, Tsikas D: Human plasma concentrations of malondialdehyde (MDA) and the F2-isoprostane 15(S)-8-iso-PGF(2alpha) may be markedly compromised by hemolysis: evidence by GC-MS/MS and potential analytical and biological ramifications. Clin Biochem 2010;43:159-167.

34 Lee HT, Lin CS, Lee CS, Tsai CY, Wei YH: Increased 8-hydroxy-2'-deoxyguanosine in plasma and decreased mRNA expression of human 8-oxoguanine DNA glycosylase 1, anti-oxidant enzymes, mitochondrial biogenesisrelated proteins and glycolytic enzymes in leucocytes in patients with systemic lupus erythematosus. Clin Exp Immunol 2014;176:66-77.

35 Buchowski MS, Hongu N, Acra S, Wang L, Warolin J, Roberts LJ 2nd: Effect of modest caloric restriction on oxidative stress in women, a randomized trial. PloS One 2012;7:5.

36 Chae JS, Paik JK, Kang R, Kim M, Choi Y, Lee SH, Lee JH: Mild weight loss reduces inflammatory cytokines, leukocyte count, and oxidative stress in overweight and moderately obese participants treated for 3 years with dietary modification. Nutr Res 2013;33:195-203.

37 Gutierrez-Lopez L, Garcia-Sanchez JR, Rincon-Viquez Mde J, Lara-Padilla E, Sierra-Vargas MP, Olivares-Corichi IM: Hypocaloric diet and regular moderate aerobic exercise is an effective strategy to reduce anthropometric parameters and oxidative stress in obese patients. Obes Facts 2012;5:12-22.

38 Meydani M, Das S, Band M, Epstein S, Roberts S: The effect of caloric restriction and glycemic load on measures of oxidative stress and antioxidants in humans: results from the CALERIE Trial of Human Caloric Restriction. J Nutr Health Aging 2011;15:456-460.

39 Wegman MP, Guo MH, Bennion DM, Shankar MN, Chrzanowski SM, Goldberg LA, Xu J, Williams TA, Lu X, Hsu SI, Anton SD, Leeuwenburgh C, Brantly ML: Practicality of intermittent fasting in humans and its effect on oxidative stress and genes related to aging and metabolism. Rejuvenation Res 2015;18:162-172.

40 Boesing F, Moreira EA, Wilhelm-Filho D, Vigil SV, Parizottto EB, Inacio DB, Portari GV, Trindade EB, JordaoJunior AA, Frode TS: Roux-en-Y bypass gastroplasty: markers of oxidative stress 6 months after surgery. Obes Surg 2010;20:1236-1244. 
41 Elizondo A, Araya J, Rodrigo R, Signorini C, Sgherri C, Comporti M, Poniachik J, Videla LA: Effects of weight loss on liver and erythrocyte polyunsaturated fatty acid pattern and oxidative stress status in obese patients with non-alcoholic fatty liver disease. Biol Res 2008;41:59-68.

42 Joao Cabrera E, Valezi AC, Delfino VD, Lavado EL, Barbosa DS: Reduction in plasma levels of inflammatory and oxidative stress indicators after Roux-en-Y gastric bypass. Obes Surg 2010;20:42-49.

43 Rector RS, Warner SO, Liu Y, Hinton PS, Sun GY, Cox RH, Stump CS, Laughlin MH, Dellsperger KC, Thomas TR: Exercise and diet induced weight loss improves measures of oxidative stress and insulin sensitivity in adults with characteristics of the metabolic syndrome. Am J Physiol Endocrinol Metab 2007;293:E500-506.

44 Roberts CK, Won D, Pruthi S, Kurtovic S, Sindhu RK, Vaziri ND, Barnard RJ: Effect of a short-term diet and exercise intervention on oxidative stress, inflammation, MMP-9, and monocyte chemotactic activity in men with metabolic syndrome factors. J Appl Physiol (1985) 2006;100:1657-1665.

45 Wycherley TP, Brinkworth GD, Noakes M, Buckley JD, Clifton PM: Effect of caloric restriction with and without exercise training on oxidative stress and endothelial function in obese subjects with type 2 diabetes. Diabetes Obes Metab 2008;10:1062-1073.

46 Duggan C, Tapsoba JD, Wang CY, Campbell KL, Foster-Schubert K, Gross MD, McTiernan A: Dietary weight loss, exercise, and oxidative stress in postmenopausal women: a randomized controlled trial. Cancer Prev Res (Phila) 2016;9:835-843.

47 Abd El-Kader SM, Saiem Al-Dahr MH: Impact of weight loss on oxidative stress and inflammatory cytokines in obese type 2 diabetic patients. Afr Health Sci 2016;16:725-733.

48 Schmatz R, Bitencourt MR, Patias LD, Beck M, da CAG, Zanini D, Gutierres JM, Diehl LN, Pereira LB, Leal CA, Duarte MF, Schetinger MR, Morsch VM: Evaluation of the biochemical, inflammatory and oxidative profile of obese patients given clinical treatment and bariatric surgery. Clin Chim Acta 2017;465:72-79.

49 National Association for Weight Loss Surgery. Weight Loss Surgery Statistics and Definitions: www.nawls. $\mathrm{com} /$ public/102.cfm (last accessed November 28, 2017).

50 Martinez de la Escalera L, Kyrou I, Vrbikova J, Hainer V, Sramkova P, Fried M, Piya MK, Kumar S, Tripathi G, McTernan PG: Impact of gut hormone FGF-19 on type-2 diabetes and mitochondrial recovery in a prospective study of obese diabetic women undergoing bariatric surgery. BMC Med 2017;15:34.

51 Hoeijmakers JH: DNA damage, aging, and cancer. N Engl J Med 2009;361:1475-1485.

52 Goode EL, Ulrich CM, Potter JD: Polymorphisms in DNA repair genes and associations with cancer risk. Cancer Epidemiol Biomarkers Prev 2002;11:1513-1530.

53 Negrini S, Gorgoulis VG, Halazonetis TD: Genomic instability - an evolving hallmark of cancer. Nat Rev Mol Cell Biol 2010;11:220-228.

54 Habermann N, Makar KW, Abbenhardt C, Xiao L, Wang CY, Utsugi HK, Alfano CM, Campbell KL, Duggan C, Foster-Schubert KE, Mason CE, Imayama I, Blackburn GL, Potter JD, McTiernan A, Ulrich CM: No effect of caloric restriction or exercise on radiation repair capacity. Med Sci Sports Exerc 2015;47:896-904.

55 Heilbronn LK, de Jonge L, Frisard MI, DeLany JP, Larson-Meyer DE, Rood J, Nguyen T, Martin CK, Volaufova J, Most MM, Greenway FL, Smith SR, Deutsch WA, Williamson DA, Ravussin E: Effect of 6-month calorie restriction on biomarkers of longevity, metabolic adaptation, and oxidative stress in overweightindividuals: a randomized controlled trial. JAMA 2006;295:1539-1548.

56 Shammas MA: Telomeres, lifestyle, cancer, and aging. Curr Opin Clin Nutr Metab Care 2011;14:28-34.

57 Hanahan D, Weinberg RA: Hallmarks of cancer: the next generation. Cell 2011;144:646-674.

58 Aviv A: The epidemiology of human telomeres: faults and promises. J Gerontol A, Biol Sci Med Sci 2008;63: 979-983.

59 Mundstock E, Sarria EE, Zatti H, Mattos Louzada F, Kich Grun L, Herbert Jones M, Guma FT, Mazzola In Memoriam J, Epifanio M, Stein RT, Barbe-Tuana FM, Mattiello R: Effect of obesity on telomere length: systematic review and meta-analysis. Obesity (Silver Spring) 2015;23:2165-2174.

60 Carulli L, Anzivino C, Baldelli E, Zenobii MF, Rocchi MB, Bertolotti M: Telomere length elongation after weight loss intervention in obese adults. Mol Genet Metab 2016;118:138-142.

61 Formichi C, Cantara S, Ciuoli C, Neri O, Chiofalo F, Selmi F, Tirone A, Colasanto G, Di Cosmo L, Vuolo G, Pacini F: Weight loss associated with bariatric surgery does not restore short telomere length of severe obese patients after 1 year. Obes Surg 2014;24:2089-2093.

62 Skrha J, Kunesová M, Hilgertová J, Weiserová H, Krízová J, Kotrlíková E: Short-term very low calorie diet reduces oxidative stress in obese type 2 diabetic patients. Physiol Res 2005;54:33-39. 